\title{
Days' Supply of Initial Opioid Analgesic Prescriptions and Additional Fills for Acute Pain Conditions Treated in the Primary Care Setting — United States, 2014
}

\author{
Mallika L. Mundkur, MD¹; Jessica M. Franklin, $\mathrm{PhD}^{2}$; Younathan Abdia, $\mathrm{PhD}^{2}$; Krista F. Huybrechts, $\mathrm{PhD}^{2}$; Elisabetta Patorno, $\mathrm{MD}$, DrPH${ }^{2}$; \\ Joshua J. Gagne, PharmD, ScD ${ }^{2}$; Tamra E. Meyer, $\mathrm{PhD}^{1}$; Judy Staffa, $\mathrm{PhD}^{1}$; Brian T. Bateman, $\mathrm{MD}^{2}$
}

During 2017, opioids were associated with 47,600 deaths in the United States, approximately one third of which involved a prescription opioid (1). Amid concerns that overprescribing to patients with acute pain remains an essential factor underlying misuse, abuse, diversion, and unintentional overdose, several states have restricted opioid analgesic prescribing $(2,3)$. To characterize patterns of opioid analgesic use for acute pain in primary care settings before the widespread implementation of limits on opioid prescribing $(2,3)$, patients filling an opioid analgesic prescription for acute pain were identified from a 2014 database of commercial claims. Using a logistic generalized additive model, the probability of obtaining a refill was estimated as a function of the initial number of days supplied. Among 176,607 patients with a primary care visit associated with an acute pain complaint, $7.6 \%$ filled an opioid analgesic prescription. Among patients who received an initial 7-day supply, the probability of obtaining an opioid analgesic prescription refill for nine of 10 conditions was $<25 \%$. These results suggest that a $\leq 7$-day opioid analgesic prescription might be sufficient for most, but not all, patients seen in primary care settings with acute pain who appear to need opioid analgesics. However, treatment strategies should account for patient and condition characteristics, which might alternatively reduce or extend the anticipated duration of benefit from opioid analgesic therapy.

This analysis was based on a previously defined cohort used to characterize national patterns of prescribing for acute pain in primary care settings; details of cohort selection are described elsewhere (4). Briefly, adults who filled an opioid analgesic prescription within 7 days of an initial visit for any of 10 common acute pain conditions (back pain with radiculopathy, back pain without radiculopathy, neck pain, joint pain, tendon/bursal pain, muscle strains/sprains, musculoskeletal injury [e.g., ligamentous tears], urinary calculus, headache, and dental pain) evaluated in a primary care setting were identified using 2014 data from a large U.S. nationwide commercial insurer. The cohort excluded patients with history of previous opioid use, substance abuse, cancer, admission to hospice/hospital, or surgery during a baseline claims history of 6 months. Patients filling prescriptions for $\geq 30$ days or for patch formulations also were excluded from this analysis on the assumption that, for these patients, clinicians intended to initiate long-term therapy. Patients who had $<30$ days of follow-up or who had multiple pain conditions or multiple opioid analgesic prescriptions associated with the index primary care visit also were excluded. Patients included in the analysis could not have more than one of the 10 acute pain conditions (i.e., only a patient's first visit to a primary care provider that met inclusion criteria for the study was included in the analysis). Two statistical software packages were used to conduct the analyses: SAS (version 9.4; SAS Institute) and R (version 3.5.0; R Foundation for Statistical Computing).

The primary outcome of interest was opioid analgesic refills; any additional fill for oral opioid analgesics during the 30 days after the index fill was considered a refill. Refills were presumed to be an indication that the initial amount of medication prescribed was perceived as insufficient for the treatment of the patient's pain (5). Descriptive statistics concerning the number of days' supply, quantity dispensed, and morphine milligram equivalents of the index dispensing were calculated.

A logistic generalized additive model was fit for the probability of a refill as a smooth function of prescribed days' supply separately for each condition $(5,6)$. Models were first fit without adjustment for covariates, so that the number of days' supply of the initial opioid analgesic fill was the only variable in the model; models were then fit with adjustment for age, sex, and Charlson comorbidity score (an index for estimating mortality from comorbid conditions in longitudinal studies) (7). Age was included in the model using a smooth term to allow for nonlinearity of the association between age and outcome. This model was used to estimate the probability of a refill associated with an initial supply of $3,5,7,14$, or 28 days for the average patient with each condition.

Among the 176,607 patients meeting selection criteria with a visit to a primary care setting for an episode of acute pain, a total of 13,440 (7.6\%) filled an opioid analgesic prescription within 7 days of the initial visit; the percentage varied by condition, from 1,229 (3.5\%) for headache to 302 (27.6\%) for dental pain (Table 1). Among patients who filled a prescription for opioid analgesics, the median initial amount filled across conditions ranged from 4-7 days, 20-30 tablets or capsules, and 100-155 morphine milligram equivalents. A total of 2,392 $(17.8 \%)$ patients who were dispensed an opioid analgesic (i.e., approximately $1 \%$ of the full cohort) obtained at least one 
refill within 30 days after their initial prescription. Higher unadjusted rates of refills occurred among men (19.3\%) than among women (15.8\%), as well as among patients with recent history of use of benzodiazepines (26.5\%), sedative hypnotics (20.0\%), or gabapentin (28.3\%), relative to the overall refill rate $(17.8 \%)$ (Table 1$)$.

The adjusted probability of a refill appeared to decrease with increasing initial prescription duration for some conditions (e.g., back pain with radiculopathy, nephrolithiasis, or dental pain), whereas for other conditions, the adjusted probability of a refill remained relatively constant regardless of the amount initially prescribed (e.g., joint pain or nonradicular back pain) (Table 2). For an initial prescription of 7 days, the adjusted probability of refill ranged from 0.11 (95\% confidence interval $=0.09-0.14)$ for headache to 0.41 (0.19-0.68) for musculoskeletal injury (Table 2).

\section{Discussion}

These findings, drawn from the claims of nationwide commercial insurance beneficiaries, indicate that in 2014 the median duration of initial opioid analgesic prescriptions for acute pain indications in a primary care setting was 4-7 days. Fewer than one in five patients who filled an opioid analgesic prescription received a refill, suggesting that in most cases an initial prescription of this duration was considered sufficient (and possibly even more than necessary) for patients seen in primary care settings with acute pain, consistent with recommendations in the 2016 CDC Guideline for Prescribing Opioids for Chronic Pain (8). These results also suggest that providing a 7-day supply might risk overtreatment for some of these conditions. However, depending upon the specific condition, the probability of receiving a refill after an initial 7-day supply ranged from $0.11-0.41$, underscoring the potential variation among patients in time to recovery and variation in clinician practice, as well as possible variation in availability of nonopioid treatment methods. Because legal limits on prescribing are imposed despite such variation, these results suggest that health systems will need to be equipped to provide efficient mechanisms for opioid analgesic refills when they are clinically appropriate $(9,10)$.

The findings in this report are subject to at least four limitations. First, this analysis preceded the implementation of many

TABLE 1. Quantity of opioid analgesics filled after initial visits for acute pain in primary care settings, by patient characteristics — United States, 2014

\begin{tabular}{|c|c|c|c|c|c|c|}
\hline Characteristic & $\begin{array}{l}\text { No. of patients } \\
\text { with visit for } \\
\text { acute pain }\end{array}$ & $\begin{array}{l}\text { No. of patients } \\
\text { with opioid fill } \\
\text { within } 7 \text { days of } \\
\text { initial visit (\%) }\end{array}$ & $\begin{array}{c}\text { Index fill: no. of days' } \\
\text { supply dispensed,* } \\
\text { median (IQR) (10th } \\
\text { percentile) (90th } \\
\text { percentile) }\end{array}$ & $\begin{array}{l}\text { Index fill: no. of } \\
\text { tablets/capsules } \\
\text { dispensed,* median } \\
\text { (IQR) (10th percentile) } \\
\text { (90th percentile) }\end{array}$ & $\begin{array}{l}\text { Index fill total } \\
\text { MME dispensed,* } \\
\text { median (IQR) } \\
\text { (10th percentile) } \\
\text { (90th percentile) }\end{array}$ & $\begin{array}{l}\text { No. of patients with } \\
\geq 1 \text { refill }(\%)^{*}\end{array}$ \\
\hline \multicolumn{7}{|l|}{ Sex } \\
\hline Women & 88,831 & $5,815(6.5)$ & $7(4-10)(3-15)$ & $30(20-40)(15-60)$ & $150(100-225)(75-300)$ & $918(15.8)$ \\
\hline Men & 87,776 & $7,625(8.7)$ & $7(4-10)(3-15)$ & $30(20-40)(15-60)$ & $150(100-225)(75-338)$ & $1,474(19.3)$ \\
\hline \multicolumn{7}{|l|}{ Baseline medication } \\
\hline Benzodiazepines & 6,291 & $810(12.9)$ & $7(5-10)(3-15)$ & $30(20-40)(15-60)$ & $150(120-250)(90-375)$ & $215(26.5)$ \\
\hline Sedative hypnotics & 4,325 & $375(8.7)$ & $7(5-10)(3-15)$ & $30(21-40)(15-60)$ & $150(150-300)(100-480)$ & $75(20.0)$ \\
\hline Gabapentinoids & 1,515 & $187(12.3)$ & $8(5-13)(4-15)$ & $30(30-60)(16-75)$ & $200(150-300)(90-450)$ & $53(28.3)$ \\
\hline \multicolumn{7}{|c|}{ Baseline Charlson comorbidity score ${ }^{\dagger}$} \\
\hline 0 & 152,669 & $11,680(7.7)$ & $6(4-10)(3-15)$ & $30(20-40)(15-60)$ & $150(100-225)(75-300)$ & $2,071(17.7)$ \\
\hline 1 & 19,462 & $1,406(7.2)$ & $7(5-10)(3-15)$ & $30(20-40)(15-60)$ & $150(120-300)(100-400)$ & $256(18.2)$ \\
\hline 2 & 3,533 & $279(7.9)$ & $8(5-12)(3-15)$ & $30(30-50)(20-60)$ & $200(150-300)(100-450)$ & $48(17.2)$ \\
\hline$\geq 3$ & 943 & $75(8.0)$ & $8(5-11)(4-15)$ & $30(20-50)(15-60)$ & $150(150-300)(100-450)$ & $17(22.7)$ \\
\hline \multicolumn{7}{|l|}{ Pain conditions ${ }^{\S}$} \\
\hline Joint pain & 56,474 & $2,761(4.9)$ & $7(5-10)(3-15)$ & $30(20-40)(15-60)$ & $150(113-250)(80-400)$ & $521(18.9)$ \\
\hline $\begin{array}{l}\text { Back pain without } \\
\text { radiculopathy }\end{array}$ & 41,862 & $5,602(13.4)$ & $7(5-10)(3-15)$ & $30(20-40)(15-60)$ & $150(100-225)(75-300)$ & $922(16.5)$ \\
\hline Headache & 34,718 & $1,229(3.5)$ & $6(4-10)(3-15)$ & $30(20-40)(12-100)$ & $150(100-240)(75-600)$ & $144(11.7)$ \\
\hline Neck pain & 11,943 & $1,101(9.2)$ & $7(4-10)(3-15)$ & $30(20-40)(15-60)$ & $150(100-225)(75-300)$ & $216(19.6)$ \\
\hline Tendonitis/Bursitis & 13,371 & $457(3.4)$ & $7(4-10)(3-15)$ & $30(20-40)(15-60)$ & $150(100-225)(75-300)$ & $81(17.7)$ \\
\hline $\begin{array}{l}\text { Muscular strains/ } \\
\text { Sprains }\end{array}$ & 9,034 & $812(9.0)$ & $5(3-7)(2-10)$ & $20(20-30)(12-42)$ & $120(100-150)(75-300)$ & $132(16.3)$ \\
\hline $\begin{array}{l}\text { Back pain with } \\
\text { radiculopathy }\end{array}$ & 3,925 & $684(17.4)$ & $7(5-10)(3-15)$ & $30(20-40)(15-60)$ & $150(120-225)(100-300)$ & $203(29.7)$ \\
\hline Nephrolithiasis & 2,980 & $422(14.2)$ & $5(3-8)(2-10)$ & $26.5(20-30)(15-50)$ & $150(100-225)(75-300)$ & $81(19.2)$ \\
\hline Musculoskeletal injury & 1,205 & $70(5.8)$ & $7(4-10)(3-15)$ & $30(20-40)(15-60)$ & $155(125-225)(95-425)$ & $21(30.0)$ \\
\hline Dental pain & 1,095 & $302(27.6)$ & $4(3-6)(2-10)$ & $20(15-30)(12-30)$ & $100(75-150)(60-225)$ & $71(23.5)$ \\
\hline
\end{tabular}

Abbreviations: $\mathrm{IQR}=$ interquartile range; $\mathrm{MME}=$ morphine milligram equivalents

* Among patients with at least one fill for opioids for an episode of acute pain.

† An index for estimating mortality from comorbid conditions in longitudinal studies. https://www.ncbi.nlm.nih.gov/pubmed/3558716.

$\S$ Additional detail regarding International Classification of Diseases, Ninth Revision codes used to define conditions. https://www.ncbi.nlm.nih.gov/pubmed/28971545. 
Morbidity and Mortality Weekly Report

TABLE 2. Crude and adjusted* probabilities of refill by number of days initially supplied and acute pain condition

\begin{tabular}{|c|c|c|c|c|c|}
\hline \multirow[b]{2}{*}{ Condition } & \multicolumn{5}{|c|}{ No. of days initially supplied $(95 \% \mathrm{Cl})$} \\
\hline & 3 & 5 & 7 & 14 & 28 \\
\hline \multicolumn{6}{|l|}{ Joint pain } \\
\hline Crude & $0.20(0.18-0.23)$ & $0.20(0.18-0.22)$ & $0.20(0.18-0.22)$ & $0.18(0.16-0.21)$ & $0.12(0.05-0.24)$ \\
\hline Adjusted & $0.20(0.17-0.22)$ & $0.20(0.18-0.22)$ & $0.20(0.18-0.22)$ & $0.18(0.16-0.22)$ & $0.12(0.05-0.25)$ \\
\hline \multicolumn{6}{|c|}{ Back pain without radiculopathy } \\
\hline Crude & $0.17(0.16-0.19)$ & $0.17(0.16-0.18)$ & $0.16(0.15-0.17)$ & $0.15(0.13-0.17)$ & $0.12(0.09-0.17)$ \\
\hline Adjusted & $0.16(0.14-0.18)$ & $0.16(0.14-0.17)$ & $0.15(0.14-0.17)$ & $0.14(0.12-0.16)$ & $0.11(0.08-0.16)$ \\
\hline \multicolumn{6}{|l|}{ Headache } \\
\hline Crude & $0.14(0.11-0.17)$ & $0.13(0.11-0.15)$ & $0.12(0.097-0.14)$ & $0.10(0.07-0.15)$ & $0.12(0.03-0.38)$ \\
\hline Adjusted & $0.13(0.10-0.16)$ & $0.12(0.093-0.14)$ & $0.11(0.086-0.14)$ & $0.09(0.07-0.14)$ & $0.10(0.02-0.31)$ \\
\hline \multicolumn{6}{|l|}{ Neck pain } \\
\hline Crude & $0.22(0.18-0.25)$ & $0.21(0.18-0.24)$ & $0.20(0.18-0.22)$ & $0.17(0.13-0.22)$ & $0.13(0.06-0.26)$ \\
\hline Adjusted & $0.25(0.20-0.30)$ & $0.23(0.19-0.28)$ & $0.22(0.19-0.26)$ & $0.19(0.14-0.25)$ & $0.13(0.06-0.26)$ \\
\hline \multicolumn{6}{|c|}{ Tendonitis/Bursitis } \\
\hline Crude & $0.17(0.12-0.22)$ & $0.17(0.13-0.21)$ & $0.17(0.14-0.21)$ & $0.18(0.12-0.26)$ & $0.21(0.07-0.48)$ \\
\hline Adjusted & $0.17(0.12-0.23)$ & $0.17(0.13-0.22)$ & $0.18(0.14-0.22)$ & $0.19(0.12-0.27)$ & $0.21(0.07-0.49)$ \\
\hline \multicolumn{6}{|c|}{ Muscular strains/Sprains } \\
\hline Crude & $0.17(0.13-0.20)$ & $0.16(0.13-0.19)$ & $0.15(0.12-0.18)$ & $0.13(0.07-0.21)$ & $0.09(0.02-0.31)$ \\
\hline Adjusted & $0.16(0.13-0.20)$ & $0.16(0.13-0.19)$ & $0.15(0.12-0.18)$ & $0.13(0.07-0.22)$ & $0.09(0.02-0.32)$ \\
\hline \multicolumn{6}{|c|}{ Back pain with radiculopathy } \\
\hline Crude & $0.31(0.24-0.39)$ & $0.33(0.27-0.40)$ & $0.28(0.21-0.35)$ & $0.21(0.12-0.34)$ & $-^{\dagger}$ \\
\hline Adjusted & $0.24(0.16-0.35)$ & $0.27(0.20-0.36)$ & $0.21(0.14-0.30)$ & $0.15(0.07-0.29)$ & $-^{\dagger}$ \\
\hline \multicolumn{6}{|c|}{ Nephrolithiasis } \\
\hline Crude & $0.21(0.16-0.26)$ & $0.20(0.16-0.25)$ & $0.20(0.15-0.25)$ & $0.18(0.08-0.35)$ & $0.15(0.02-0.61)$ \\
\hline Adjusted & $0.22(0.15-0.31)$ & $0.22(0.15-0.29)$ & $0.21(0.14-0.30)$ & $0.19(0.08-0.39)$ & $0.16(0.02-0.65)$ \\
\hline \multicolumn{6}{|c|}{ Musculoskeletal injury } \\
\hline Crude & $0.26(0.12-0.47)$ & $0.49(0.27-0.72)$ & $0.37(0.18-0.62)$ & $0.41(0.13-0.77)$ & $-^{\dagger}$ \\
\hline Adjusted & $0.21(0.086-0.44)$ & $0.55(0.30-0.79)$ & $0.41(0.19-0.68)$ & $0.48(0.15-0.84)$ & $-^{\dagger}$ \\
\hline \multicolumn{6}{|c|}{ Dental pain } \\
\hline Crude & $0.27(0.21-0.33)$ & $0.23(0.19-0.29)$ & $0.20(0.14-0.28)$ & $0.12(0.04-0.31)$ & $0.04(0.003-0.39)$ \\
\hline Adjusted & $0.27(0.21-0.33)$ & $0.23(0.18-0.29)$ & $0.20(0.14-0.28)$ & $0.12(0.04-0.31)$ & $0.04(0.003-0.39)$ \\
\hline
\end{tabular}

Abbreviation: $\mathrm{Cl}=$ confidence interval.

* Adjusted for age, sex, and Charlson comorbidity score. https://www.ncbi.nlm.nih.gov/pubmed/3558716. Probabilities calculated for the "average patient."

† Estimate is not informative because of sparse data. 28 days' supply estimates are outside the range of data for most conditions.

prescribing limits on opioids (2,3). Accordingly, compared with filling behaviors observed during the period assessed by this study (i.e., 2014), observed filling behaviors in more recent years might be distinct, potentially influenced by factors external to the patient-physician interaction, including policies enforced by states, health systems, or private stakeholders. Second, although absence of a refill was used as a surrogate for adequacy of the initially dispensed supply for controlling pain, in addition to a need for additional opioid therapy, opioid refills might reflect physical dependence, withdrawal, or the need for additional pain control that could possibly be managed by nonopioid alternatives. Third, refills within 30 days of an initial opioid fill were presumed to be for treatment of the same pain condition as the initial fill, although given the lack of direct linkage between the diagnostic and prescription claims, this assumption could not be verified. Finally, certain patient characteristics, such as male sex and recent use of benzodiazapenes, were associated with higher refill rates; however, these associations should be interpreted with caution because these factors might be associated with conditions requiring longer duration of treatment rather than being independent risk factors for additional fills. Although efforts were made to stratify analyses on distinct pain etiologies targeted by opioid analgesic prescribing in the primary care setting, some heterogeneity with respect to etiology, duration, and severity of pain within these categories is likely.

Future research could aim to further clarify the natural history of acute pain across a range of settings and conditions and to identify the risks and benefits of opioid analgesic use for acute pain through in-depth prospective interviews with patients. Simultaneously, research to evaluate the impact of recent opioid analgesic prescribing guidelines upon patientcentered outcomes including, but not limited to, adequacy of pain control, misuse of opioids, or development of opioid use disorder, is needed. Such measures might help determine whether existing strategies to regulate opioid analgesic prescribing result in an acceptable benefit-to-harms ratio. The findings in this report suggest that for several acute pain conditions 


\section{Summary}

What is already known about this topic?

The prescribed duration of opioid analgesics for acute pain in the primary care setting varies by patient and condition.

What is added by this report?

For 10 acute pain conditions commonly managed in primary care settings, the probability of obtaining a refill after an initial 7-day opioid analgesic prescription ranged from $11 \%$ (headache) to $41 \%$ (musculoskeletal injury), with refill probability $<25 \%$ for most conditions.

What are the implications for public health practice?

Initial opioid analgesic prescriptions of $\leq 7$ days' duration appear sufficient for many patients seen in primary care settings with acute pain. Treatment strategies should account for patient- and condition-specific characteristics, which might reduce or extend duration of benefit from opioid analgesic therapy.

evaluated in primary care settings, opioid analgesics, when provided to treat pain, can generally be prescribed for durations of $\leq 7$ days. However, health systems must anticipate variation in patient, condition, and other contextual characteristics that will influence the duration and intensity of pain and adopt mechanisms to ensure that additional access to both pharmacologic and nonpharmacologic therapy is available when required.

\section{Acknowledgments}

Food and Drug Administration, Silver Spring, Maryland.

Corresponding author: Mallika Mundkur, mallika.mundkur@fda.hhs.gov, 301-796-3677.

\footnotetext{
${ }^{1}$ Office of Surveillance and Epidemiology, Center for Drug Evaluation and Research, Food and Drug Administration, Silver Spring, Maryland; ${ }^{2}$ Division of Pharmacoepidemiology and Pharmacoeconomics, Department of Medicine, Brigham and Women's Hospital and Harvard Medical School, Boston, Massachusetts.
}

All authors have completed and submitted the ICMJE form for disclosure of potential conflicts of interest. Brian Bateman reports grants from the Food and Drug Administration (FDA) during the conduct of the study; grants to Brigham and Women's Hospital (BWH) from the National Institutes of Health, Pfizer, GSK, Baxalta, Lilly, and Pacira, and personal fees from Aetion, outside the submitted work. Elisabetta Patorno reports a career development grant K08AG055670 from the National Institute on Aging. She is investigator of investigator-initiated grants to $\mathrm{BWH}$ from Boehringer Ingelheim and GSK, outside the topic of the submitted work. Jessica Franklin reports grants from FDA during the conduct of the study. Joshua Gagne reports grants from Eli Lilly and Company and Novartis Pharmaceuticals Corporation to BWH and is a consultant to Aetion, Inc. and Optum, Inc., for work unrelated to the study. Krista Huybrechts reports grants from FDA during the conduct of the study and grants to BWH from Lilly, GlaxoSmithKline, and Pfizer Boehringer Ingelheim outside the submitted work. No other potential conflicts of interest were disclosed.

\section{References}

1. Scholl L, Seth P, Kariisa M, Wilson N, Baldwin G. Drug and opioidinvolved overdose deaths-United States, 2013-2017. MMWR Morb Mortal Wkly Rep 2018;67:1419-27. https://doi.org/10.15585/mmwr. mm675152e1

2. Baker-White A. A look at state legislation limiting opioid prescriptions. Arlington, VA: Association of State and Territorial Health Officials; 2017. http://www.astho.org/StatePublicHealth/A-Look-at-State-LegislationLimiting-Opioid-Prescriptions/2-23-17/

3. American College of Physicians. Opioid prescribing: states aim to limit opioid prescriptions. Philadelphia, PA: American College of Physicians; 2018. https://acpinternist.org/archives/2016/10/laws.htm

4. Mundkur ML, Rough K, Huybrechts KF, et al. Patterns of opioid initiation at first visits for pain in United States primary care settings. Pharmacoepidemiol Drug Saf 2018;27:495-503. https://doi. org/10.1002/pds.4322

5. Scully RE, Schoenfeld AJ, Jiang W, et al. Defining optimal length of opioid pain medication prescription after common surgical procedures. JAMA Surg 2018;153:37-43. https://doi.org/10.1001/jamasurg.2017.3132

6. Wood SN. Fast stable restricted maximum likelihood and marginal likelihood estimation of semiparametric generalized linear models. J R Stat Soc B 2011;73:3-36. https://doi.org/10.1111/j.1467-9868.2010.00749.x

7. Charlson ME, Pompei P, Ales KL, MacKenzie CR. A new method of classifying prognostic comorbidity in longitudinal studies: development and validation. J Chronic Dis 1987;40:373-83. https://doi. org/10.1016/0021-9681(87)90171-8

8. Dowell D, Haegerich TM, Chou R. CDC guideline for prescribing opioids for chronic pain — United States, 2016. JAMA 2016;315:1624-45. https://doi.org/10.1001/jama.2016.1464

9. Bateman BT, Choudhry NK. Limiting the duration of opioid prescriptions: balancing excessive prescribing and the effective treatment of pain. JAMA Intern Med 2016;176:583-4. https://doi.org/10.1001/ jamainternmed.2016.0544

10. Drug Enforcement Administration. Electronic prescriptions for controlled substances (EPCS): general questions and answers. Washington, DC: US Department of Justice, Drug Enforcement Administration; 2010. https://www.deadiversion.usdoj.gov/ecomm/e_ $\mathrm{rx} / \mathrm{faq} / \mathrm{faq} \cdot \mathrm{htm}$ 